\title{
Curriculum Vitae
}

Arend L. Schwab (Arend Leendert SCHWAB)

Male, 6 April 1955, Naarden, The Netherlands

married to Ellen Peper, three children

Delft Univeristy of Technology

Mechanical Engineering (3mE)

Mekelweg 2, 2628 CD Delft, The Netherlands

email: a.l.schwab@tudelft.nl

web: http://bicycle.tudelft.nl/schwab/

\section{Expertise \& Research}

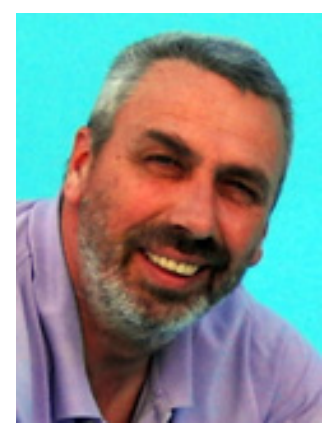

Theoretical and Applied Mechanics. Dynamics of mechanical systems. Multibody dynamics; in particular flexible bodies and rolling contact. Classical Mechanics; in particular Nonlinear Dynamics and Structural Mechanics. Finite Element Methods. Biomechanics; in particular Mechanics and Dynamics of locomotion, walking robots, speed skating and x-country skiing. Vehicle Dynamics and Control; in particular Bicycle Dynamics and Control.

\author{
Education \& Employment \\ 1991-present Assitant Professor, Delft University of Technology, The Netherlands, Faculty of Mechanical \\ Engineering (3mE), Laboratory for Engineering Mechanics (PME). \\ 2002-2003 Visiting Professor (sabbatical leave) at Cornell University, Ithaca NY, USA, Department of \\ Theoretical en Applied Mechanics. Host: Prof. Andy Ruina PhD. \\ 2002 (April) PhD at Delft University of Technology, Dynamics of Flexible Multibody Systems; Small \\ Vibrations Superimposed on a General Rigid Body Motion. \\ Advisor: Prof. dr. ir. P. Meijers. \\ 1983-1991 Assistant Professor, Delft University of Technology, Faculty of Mechanical Engineering, \\ Department of Computer Aided Design. \\ 1983 (Nov.) MSc (cum laude) at Delft University of Technology, Dynamics of Mechanisms with \\ Compliant Links. Advisor: Prof. dr. ir. J.F.Besseling. \\ 1981-1983 Teaching Assistant, Delft University of Technology, Faculty of Mechanical Engineering, \\ Laboratory for Engineering Mechanics. \\ 1979-1981 Military service, enlisted, reserve officer rank 1th lieutenant. \\ 1979 (July) BSc (cum laude) in Mechanical Engineering at Polytechnical School Dordrecht, $A$ \\ FORTRAN program for FEM analysis of 3D beam and truss structures.
}

\section{Professional Activities}

\section{International Organizations}

1998-present

2006-present

2013

2007
Member ASME, American Society of Mechanical Engineers.

Dutch Chair of member organization of the IFToMM, International Federation for the

Promotion of Mechanism and Machine Science (together with Dr. Just Herder).

Chair of the Mechanical and Electrical Engineering (MEE) review panel for evaluation of grant applications for the Research Council for Natural Sciences and Engineering of the Academy of Finland, Feb 8, 2013, Helsinki, Finland.

Member of the panel for evaluation of grant applications in mechanical engineering for the Research Council for Natural Sciences and Engineering of the Academy of Finland, May 30, 2007, Helsinki, Finland. 
Journals

2008-present

2010-present

2011

2002-present
Board member of the Journal Multibody System Dynamics, ISSN: 1384-5640.

Associate editor of the ASME Journal of Computational and Nonlinear Dynamics, ISSN: 1555-1415.

Guest editor Vehicle System Dynamics, ISSN: 0042-3114, special issue on Bicycle and Motorcycle Dynamics (with J.P.Meijaard).

Reviewer for international journals, including: J. Multibody System Dynamics; J.

Computational and Nonlinear Dynamics; Mechanism and Machine Theory; Proceedings of the Royal Society A; J. of Biomechanics; Int. J. Robotics Research; IEEE Transactions on Robotics; J. Mechanical Design.

\section{Conferences}

2013 Co-organizer of the Biomechanics session at the ECCOMAS thematic conference Multibody Dynamics 2013, 1-4 July, Zagreb, Croatia.

2012 Co-organizer of an invited session Single Track Vehicle Dynamics and Control at the 5th Annual Dynamic Systems and Control Conference and 11th Motion and Vibration Conference, ASME DSCC/MOVIC 2012, 17-19 October, 2012, Fort Lauderdale, FI, USA.

2011 Co-organizer of the Symposium on Dynamics of Land, Sea, Air, and Space Vehicles, at the 8th ASME International Conference on Multibody Systems, Nonlinear Dynamics and Control (MSNDC), 29-31 Aug 2011, Washington, DC, USA.

2011 Organizer of the Bicycle and Motorcycle Symposium BMD2010, Delft University of Technology, 20-22 Oct 2011, Delft, The Netherlands, (together with J.P.Meijaard), http://bicycle.tudelft.nl/bmd2010/

2009 Co-organizer of the Symposium on Railroad Vehicle Systems Dynamics at the DETC ASME 2009 conference, Aug 30 - Sep 2, 2009, San Diego, CA, USA.

2008 Co-organizer of the Symposium Advances in Contact Mechanics: A Tribute to J. J. Kalker, Delft University of Technology, 6-8 Oct, 2008, Delft, The Netherlands, http://www.contactmechanics.org/

2007 Co-organizer of the Symposium on Railroad Vehicle Systems Dynamics at the DETC ASME 2007 conference, Sep 4--7, 2007, Las Vegas, Nevada, USA.

2005 Co-organizer of the Symposium on Railroad Vehicle Systems Dynamics at the DETC ASME 2005 conference, Sep 10--13, 2006, Philadelphia PA, USA. Co-organizer of the 2004 Asian Conference on Multibody Dynamics, Aug 1--4, 2004, Seoul, Korea.

\section{Invited Talks}

2012 Bicycle Dynamics and Control, Feb 2012, University of Oxford, UK.

2012 Bicycle Dynamics and Design, National Machine Design Symposium, 18-19 June 2012, Uusikaupunki, Finland.

2012 Lecture series on Bicycle Dynamics for the Summer School, Multibody Dynamics in Practical Use, 4-8 June 2012, Lappeenranta, Finland

2011Multibody Dynamics and Locomotion, 2011 Workshop on Multibody Dynamics, Sep 3, University of Illinois at Chicago (UIC), Chicago, USA.

2011 Bicycle Dynamics and Control, June 2011, University of Padua, Italy.

2011Bicycle Dynamics and Control, Feb 2011, University of Glasgow, UK.

2010 Bicycle Dynamics and Control, for the Finish Graduate school on Intelligent Machines and Transport Systems, Dec 12-16, 2010, University of Seville, Seville, Spain.

2009Some Observations on Human Control of a Bicycle, Jan 2009, University of Karlsruhe, Germany.

2007 Benchmark Problems in Flexible Multibody Dynamics, 2007 Workshop on Multibody Dynamics, Sep 3, University of Illinois at Chicago (UIC), Chicago, USA.

2007Dynamics and Stability of Man-Powered Systems, Keynote address 2007 Arctic Summer Conference on Dynamics, Vibration and Control, Aug 6--10, Ivalo, Finland.

2006Bicycle Dynamics, March 9, Department of Mechanical Engineering, Lappeenranta University of Technology, Finland.

2005Recent Developments in Passive Dynamic Walking Robots and Bicycle Dynamics, Keynote address Third Arctic-Mediterranean Post Graduate Workshop on Intelligent Machines and Transport Systems, Nov 13--20, 2005, University of Seville, Seville, Spain. 
2005Bicycle Dynamics, Oct 5, Department of Theoretical and Applied Mechanics (TAM), Cornell University, Ithaca, NY, USA.

2005Benchmark Results on the Stability of an Uncontrolled Bicycle, May 16, Department of Applied Mathematics and Theoretical Physics (DAMTP), University of Cambridge, UK.

2005Recent Developments in Passive Dynamic Walking Robots, May 13, School of MMME, The University of Nottingham, UK.

2004SPACAR: A Finite Element Approach in Flexible Multibody Dynamics, Sep 27, University of Illinois at Chicago (UIC), Chicago, USA.

2003Modelling of Rolling Contact in a Multibody Environment, Workshop on Multibody System Dynamics, May 12, University of Illinois at Chicago (UIC), Chicago, USA.

2003Stability of an Uncontrolled Bicycle, Oct 24, School of MMME, The University of Nottingham, UK.

2001 Basin of attraction of the simplest walker, Sep 14, Department of Theoretical and Applied Mechanics (TAM), Cornell University, Ithaca, NY, USA.

1999The wheel as a special finite element for modelling rolling contact in a multibody dynamics environment, April 21, Université catholique de Louvain, Louvain-la-Neuve, Belgium.

\section{Dissertation Committees}

2011 Vladimir Dospel, advisor: Prof. Erno Keskinen PhD, Faculty of Automation, Mechanical and Materials Engineering, Tampere University of Technology, Tampere, Finland.

2011 Mark Christopher Davie, advisor: Prof. Arthur Whittaker PhD, Department of Mechanical Engineering University of Glasgow, UK.

2009 Lisa Coley, advisor: Prof. Allan Dolovich PhD, Department of Mechanical Engineering University of Saskatchewan, Saskatoon, Canada.

2008 Antti-Jussi Romppanen, advisor: Prof. Erno Keskinen PhD, Faculty of Automation, Mechanical and Materials Engineering, Tampere University of Technology, Tampere, Finland.

2006 Daniel Garcia Vallejo, advisor: Prof. Jaime Dominguez PhD, Dept of Mechanical Engineering, University of Seville, Spain.

2006 Kari E. Dufva, advisor: Prof. Aki Mikkola PhD, Dept of Mechanical Engineering, Lappeenranta University of Technology, Finland.

2004 Martijn Wisse, advisor: Prof. Frans C. T. van der Helm PhD, Dept of Mechanical Engineering, Delft University of Technology, The Netherlands.

\section{Sponsored or Funded Research Projects}

2013

2012
Co-applicant, Real-Time Feedback for Better Speed Skating Performance, STW dossier nr. 12870, in collaboration with Free University Amsterdam and InnoSportLab Thialf Speed Skate Arena (700k€)

Co-applicant, Detection and Diagnosis of Railway Track Short Wave Anomalies: DrTrack, STW dossier nr 12246, in collaboration with ProRail, Eurailscout, RailData, DeltaRail and Polytec (680k€)

\section{Teaching}

\section{Graduate courses:}

1997-present Multibody Dynamics, advanced, wb1413.

2004-present MATLAB in Engineering Mechanics, wb1443.

2002-2003 Applied Multibody Dynamics, TAM674 (Cornell).

1999-2000 Advanced Dynamics, wb1205.

1988-1990 Wind Energy Conversion, CTme5147.

\section{Undergraduate courses:}

1996-present Multibody Dynamics, introduction wb1310, wb1307.

2012-present Mechanical Vibrations, wb1216-06

1994-1996

1993-1994

1991-1996

1986-1991

Structural Mechanics, wb1102.

Statics, wb1101.

Dynamics, wb1103.

Computer Aided Design, wb3110. 


\section{Publications [h-index 10 (scopus), citations 613, *=key publication]}

\section{International refereed journal articles}

Matikainen, Marko K., Valkeapää, Antti I., Mikkola, Aki M., Schwab, A. L. (2013) A study of moderately thick quadrilateral plate elements based on the absolute nodal coordinate formulation, Multibody System Dynamics, accepted.

Schwab, A.L., de Lange, P.D.L., Moore, Jason K. (2013) Rider control identification in bicycling using lateral force perturbation tests, Proceedings of the Institution of Mechanical Engineers, Part K: Journal of Multi-body Dynamics, accepted.

Schepers, J.P., Den Brinker, B.P.L.M., De Waard, D., Twisk, D.A.M., Schwab, A.L., Smeets, J.B.J. (2013) Studying the role of vision in cycling: Critique on restricting research to fixation behaviour, Accident Analysis \& Prevention, online first.

Schwab, A. L. and Meijaard, J. P. (2013) A review on bicycle dynamics and rider control, Vehicle System Dynamics, online first, 1-32.

Schwab, A. L. and Meijaard, J. P. Kooijman, J.D.G. (2012) Lateral dynamics of a bicycle with a passive rider model: stability and controllability, Vehicle System Dynamics 50(8):1209-1224.

* Kooijman, J.D.G., Meijaard, J.P., Papadopoulos, Jim M. , Ruina, Andy, Schwab, A.L. (2011) A bicycle can be self-stable without gyroscopic or caster effects, Science 15 April 2011, 332(6027):339-342.

Moore, Jason K., Kooijman, J. D. G. , Schwab, A. L., and Hubbard, Mont (2011) Rider motion identification during normal bicycling by means of principal component analysis, Multibody System Dynamics 25(2):225-244.

Schwab, A. L. and Meijaard, J. P. (2010) Comparison of Three-Dimensional Flexible Beam Elements for Dynamic Analysis: Classical Finite Element Formulation and Absolute Nodal Coordinate Formulation", Journal of Computational and Nonlinear Dynamics 5(1):10p.

Moore, Jason K., Hubbard, Mont, Schwab, A. L., Kooijman, J. D. G. and Peterson Dale L. (2010) Statistics of bicycle rider motion, Procedia Engineering 2(2):2937-2942.

Matikainen, M., Mikkola, A. and Schwab, A. L. (2009) The quadrilateral fully-parameterized plate elements based on the absolute nodal coordinate formulation, Rakenteiden Mekaniikka (Journal of Structural Mechanics) 42(3):138-148.

Kooijman, J. D. G., Schwab, A. L., and Meijaard, J. P. (2008) Experimental validation of a model of an uncontrolled bicycle, Multibody System Dynamics 19(1-2):115-132.

Schwab, A. L. and Meijaard, J. P. (2008) De Stabiele Fiets, Nederlands Tijdschrift voor Natuurkunde 74(1):24-27.

* Meijaard, J.P., Papadopoulos, Jim M., Ruina, Andy, Schwab, A.L. (2007) Linearized dynamics equations for the balance and steer of a bicycle: a benchmark and review, Proceedings of the Royal Society $A$ 463:1955-1982.

Wisse, M., Hobbelen, D. G. E., and Schwab, A. L., (2007) Adding an upper body to passive dynamic walking robots by means of a bisecting hip mechanism, IEEE Transactions on Robotics 23(1):112-123.

Wisse, M., and Schwab, A. L. (2005) Skateboards, bicycles, and three-dimensional biped walking machines: Velocity-dependent stability by means of lean-to-yaw coupling, Int. J. Robotics Research 24(6):417-429.

Wisse, M., Schwab, A. L., Van der Linde, R. Q., and Van der Helm, F. C. T. (2005) How to Keep From Falling Forward: Elementary Swing Leg Action for Passive Dynamic Walkers, IEEE Transactions on Robotics 21(3):393-401.

Schwab, A. L., Meijaard, J. P., and Papadopoulos, J. M. (2005) Benchmark Results on the Linearized Equations of Motion of an Uncontrolled Bicycle, KSME International Journal of Mechanical Science and Technology 19(1):292-304.

Wisse, M., Schwab, A. L., and Van der Helm, F. C. T. (2004) Passive dynamic walking model with upper body, Robotica 22:681-688.

* Schwab, A. L., and Meijaard, J. P. (2003) Dynamics of Flexible Multibody Systems with Non-Holonomic Constraints: A Finite Element Approach, Multibody System Dynamics 10:107-123.

Schwab, A. L., and Meijaard, J. P. (2002) Small Vibrations Superimposed on a Prescribed Rigid Body Motion Multibody System Dynamics, Multibody System Dynamics 8:29-50.

Schwab, A. L., Meijaard, J. P., and Meijers. P. (2002) A comparison of revolute joint clearance models in the dynamic analysis of rigid and elastic mechanical systems, Mechanism and Machine Theory 37: 895-913.

Wisse, M., Schwab, A.L., and Van der Linde, R. Q. (2001) A 3D passive dynamic biped with yaw and roll compensation, Robotica 19:275-284.

Schwab, A. L., and Meijaard, J. P. (1999) Dynamics of flexible multibody systems having rolling contact: Application of the wheel element to the dynamics of road vehicles, Vehicle System Dynamics Supplement, 33:338-349.

Segla, S., Kalker-Kalkman, C. M., and Schwab, A. L. (1998) Statical balancing of a robot mechanism with the aid of a genetic algoritm, Mechanism and Machine Theory 33:163-174.

Schwab, A. L., and Werff, K. van der (1993) The use of computers in the design of discrete component systems, Computer Methods in Applied Mechanics and Engineering, 103:231-246.

* Soest, A. J. van, Schwab, A. L., Bobbert, M. F., and Ingen Schenau, G. J. van (1993) The influence of the biarticularity of the gastrocnemius muscle on vertical-jumping achievement, Journal of Biomechanics, 26:1-8.

Soest, A. J. van, Schwab, A. L., Bobbert, M. F., and Ingen Schenau, G. J. van (1992) SPACAR: a software subroutine package for simulation of the behaviour of biomechanical systems," Journal of Biomechanics, 


\section{International refereed full-paper conference publications}

Schwab, A.L., de Lange, P.D.L., Moore, Jason K. (2012) Rider optimal control identification in bicycling, In Proceedings of the ASME 2012 5th Annual Dynamic Systems and Control Conference, DSCC2012, Oct 17-19, 2012, Fort Lauderdale, FL, USA.

Schwab, A.L., Kooijman, J.D.G., Nieuwendijk, J. (2012) On the design of a recumbent bicycle with a perspective on handling qualities, In Proceedings of the ASME 2012 International Design Engineering Technical Conferences \& Computers and Information in Engineering Conference, DETC2012, Aug 12-15, 2012, Chicago, IL, USA.

Schwab, A.L., de Lange, P.D.L., Happee, R., Moore, Jason K. (2012) Rider control identification in bicycling, parameter estimation of a linear model using lateral force perturbation tests, In Proceedings of the IMSD2012 - The 2nd Joint International Conference on Multibody System Dynamics, May 29 - June 1, 2012 Stuttgart, Germany.

Kooijman, J. D. G. and Schwab, A. L. (2011) A review on handling aspects in bicycle and motorcycle control, In Proceedings of the ASME 2011 International Design Engineering Technical Conferences \& Computers and Information in Engineering Conference, DETC2011, Aug 28-31, 2011, Washington DC, USA.

Fintelman, D. M. , den Braver, O. , and Schwab, A. L. (2011) A simple 2-dimensional model of speed skating which mimics observed forces and motions, In Proceedings of the Euromech Colloquium 511, Biomechanics of Human Motion, March 9-12, 2011, Ponta Delgado, Azores, Portugal.

Schwab, A. L. and Kooijman, J. D. G. (2010) Controllability of a bicycle, In Proceedings of the 5th Asian Conference on Multibody Dynamics 2010, August 23-26, 2010, Kyoto, Japan.

Schwab, A. L. and Kooijman, J. D. G. (2010) Lateral dynamics of a bicycle with passive rider model, In Proceedings of the 1st Joint International Conference on Multibody System Dynamics, IMSD2010, May 25-27, 2010, Lappeenranta, Finland.

Zaazaa, K. E. and Schwab, A. L. (2009) Review of joost kalkers wheel-rail contact theories and their implementation in multibody codes, In Proceedings of the ASME 2009 International Design Engineering Technical Conferences \& Computers and Information in Engineering Conference, DETC2009, Aug 30 - Sep 2, 2009, San Diego, CA.

Moore, J. K., Hubbard, M., Kooijman, J. D. G. and Schwab, A. L. (2009) A method for estimating physical properties of a combined bicycle and rider, In Proceedings of the ASME 2009 International Design Engineering Technical Conferences \& Computers and Information in Engineering Conference, DETC2009, Aug 30 - Sep 2, 2009, San Diego, CA.

Kooijman, J. D. G., Schwab, A. L., and Moore, J. K. (2009) Some observations on human control of a bicycle, In Proceedings of the ASME 2009 International Design Engineering Technical Conferences \& Computers and Information in Engineering Conference, DETC2009, Aug 30 - Sep 2, 2009, San Diego, CA.

Kooijman, J. D. G. and Schwab, A. L. (2009) Experimental validation of the lateral dynamics of a bicycle on a treadmill, In Proceedings of the ASME 2009 International Design Engineering Technical Conferences \& Computers and Information in Engineering Conference, DETC2009, Aug 30 - Sep 2, 2009, San Diego, CA.

Schwab, A. L. and Meijaard, J. P. (2009) Beam benchmark problems for validation of flexible multibody dynamics codes, In M. Wojtyra K. Arczewski, J. Fraczek, editor, MULTIBODY DYNAMICS 2009, ECCOMAS Thematic Conference, 29 June-2 July 2009, Warsaw, Poland.

Moore, J. K. , Kooijman, J. D. G. and Schwab, A. L. (2009) Rider motion identification during normal bicycling by means of principal component analysis, In M. Wojtyra K. Arczewski, J. Fraczek, editor, MULTIBODY DYNAMICS 2009, ECCOMAS Thematic Conference, 29 June-2 July 2009, Warsaw, Poland.

Matikainen, M. K. , Schwab, A. L. and Mikkola, A. M. (2009) Comparison of two plate elements based on the absolute nodal coordinate formulation, In M. Wojtyra K. Arczewski, J. Fraczek, editor, MULTIBODY DYNAMICS 2009, ECCOMAS Thematic Conference, 29 June-2 July 2009, Warsaw, Poland.

Kooijman, J. D. G. and Schwab, A. L. (2008) Some Observations on Human Control of a Bicycle, In Proceedings of the 11th mini Conference on Vehicle System Dynamics, Identification and Anomalies (VSDIA2008), June 25-July 2, 2008, Budapest, Hungary, Budapest, University of Technology and Economics, 2008, 8pp.

Schwab, A. L., Kooijman, J. D. G., and Meijaard, J. P. (2008) Some recent developments in bicycle dynamics and control, In Proceedings of the Fourth European Conference on Structural Control (4ECSC), Sep. 8-12, 2008, StPetersburg, Russia, Institute of Problems in Mechanical Engineering, Russian Academy of Sciences, 2008, pp.695-702.

Kragten, G. A., Herder, J. L., and Schwab, A. L. (2008) On the influence of contact geometry on grasp stability, In Proceedings of the ASME 2008 International Design Engineering Technical Conferences \& Computers and Information in Engineering Conference, DETC2008, August 3-6, 2008, New York City, NY, USA, CD-ROM, ASME, 6 pp., paper nr. DETC2008-49400.

Schwab, A. L., Gerstmayr, J., and Meijaard, J. P. (2007) Comparison of three-dimensional flexible thin plate elements for multibody dynamic analysis: finite element formulation and absolute nodal coordinate formulation, In Proceedings of the ASME 2007 International Design Engineering Technical Conferences \& Computers and Information in Engineering Conference, IDETC/CIE 2007, September 4-7, 2007, Las Vegas, Nevada, USA, CD-ROM, ASME, New York, 12pp.

Schwab, A. L., Kalker-Kalkman, C. M. (2007) Joost J. Kalker (1933-2006): A life in rolling contact, In Proceedings of the 
ASME 2007 International Design Engineering Technical Conferences \& Computers and Information in Engineering Conference, IDETC/CIE 2007, September 4-7, 2007, Las Vegas, Nevada, USA, CD-ROM, ASME, New York, 3pp.

Schwab, A. L., Meijaard, J. P., Kooijman, J. D. G. (2007) Some recent developments in bicycle dynamics, In Proceedings of the 12th World Congress in Mechanism and Machine Science, IFToMM 2007, June 17-21, 2007, Besancon, France, CD-ROM, 6 pp.

Schwab, A. L., Meijaard, J. P. and Kooijman, J. D. G. (2006) Experimental validation of a model of an uncontrolled bicycle, In Proceedings of III European Conference on Computational Mechanics, Solids, Structures and Coupled Problems in Engineering, June 5-9, 2006, Lisbon, Portugal, CD-ROM, 16pp.

Meijaard, J. P. and Schwab, A. L. (2006) Linearized equations for an extended bicycle model, In Proceedings of III European Conference on Computational Mechanics, Solids, Structures and Coupled Problems in Engineering, June 5-9, 2006, Lisbon, Portugal, CD-ROM, 18pp.

* Schwab, A. L., and Meijaard, J. P. (2006) How to draw Euler angles and utilize Euler parameters, In Proceedings of IDETC/CIE 2006, ASME 2006 International Design Engineering Technical Conferences \& Computers and Information in Engineering Conference, September 10-13, 2006, Philadelphia, PA, CD-ROM, ASME, New York, 7pp.

Schwab, A. L., and Meijaard, J. P. (2005). “Comparison of three-dimensional flexible beam elements for dynamic analysis: finite element method and absolute nodal coordinate formulation," In Proceedings of IDETC/CIE 2005, ASME 2005 International Design Engineering Technical Conferences \& Computers and Information in Engineering Conference, September 24-28, 2005, Long Beach, CA, CD-ROM, ASME, New York, 9pp.

Schwab, A. L., and Meijaard, J. P., and J. M. Papadopoulos (2005). “'A Multibody Dynamics Benchmark on the Equations of Motion of an Uncontrolled Bicycle". Proceedings of the Fifth EUROMECH Nonlinear Dynamics Conference, ENOC-2005, August 7-12, 2005, Eindhoven University of Technology, The Netherlands, 511-521.

Herder, J. L., and Schwab, A. L. (2004). “On Dynamically Equivalent Force Systems and their Application to the Balancing of a Broom or the Stability of a Shoe Box," In Proceedings of DETC'04 ASME 2004 Design Engineering Technical Conferences and Computers and Information in Engineering Conference, September 28-October 2, 2004, Salt Lake City, Utah, USA, CD-ROM, ASME, New York, 11pp.

Schwab, A. L., and Meijaard, J. P., and J. M. Papadopoulos (2004). "'Benchmark Results on the Linearized Equations of Motion of an Uncontrolled Bicycle". Proceedings of the Second Asian Conference on Multibody Dynamics, ACMD'04, August 1-4, 2004, Seoul, Korea, The Korean Society of Mechanical Engineering, 9 pp.,

Schwab, A. L., and Meijaard, J. P. (2002). "Two Special Finite Elements for Modelling Rolling Contact in a Multibody Environment". In Nobuyuki Shimizu et al. editor, Proceedings of the First Asian Conference on Multibody Dynamics, ACMD'02, July 31 -- August 2, 2002, Iwaki, Fukushima, Japan, The Japan Society of Mechanical Engineering, pp. 386-391.

Schwab, A. L., and Meijaard, J. P. (2002). “Small Vibrations Superimposed on a Prescribed Rigid Body Motion Multibody System Dynamics". Multibody System Dynamics 8:29-50.

Schwab, A. L. (2002). Dynamics of Flexible Multibody Systems. PhD thesis, Delft University of Technology. $x+155$ pp.

Schwab, A. L., and Wisse, M. (2001). "Basin of attraction of the simplest walking model," In Proceedings of ASME Design EngineeringTechnical Conferences, September 9-12, 2001, Pittsburgh, PA, CD-ROM, ASME, New York, 9pp.

Meijaard, J. P., and Schwab, A. L. (2001). “A component mode synthesis look at planar beam elements," In Proceedings of ASME Design Engineering Technical Conferences, September 9-12, 2001, Pittsburgh, PA, CD-ROM, ASME, New York, 2001, 10pp.

Meijaard, J. P., Ockels, W. J., and Schwab, A. L. (1999). 'Modelling of the dynamic behaviour of a laddermill, a novel concept to exploit wind energy'. In Proceedings Third International Symposium on Cable Dynamics, Trondheim (Norway), 16-18 August 1999, A.I.M., Liege, pp.229-234.

Schwab, A. L., and Meijaard, J. P. (1999). "'The belt, gear, bearing and hinge as special finite elements for kinematic and dynamic analysis of mechanisms and machines," In Leinonen, T. (ed.), Proceedings of the Tenth World Congress on the Theory of Machines and Mechanisms, IFToMM, June 20-24, 1999, Oulu, Finland, Oulu University Press, Vol 4, pp. 1674-1679.

Meijaard, J. P., and Schwab, A. L. (1999). “A systematic approach to the analysis of rotor dynamic systems," In Leinonen, T. (ed.), Proceedings of the Tenth World Congress on the Theory of Machines and Mechanisms, IFToMM, June 20--24, 1999, Oulu, Finland, Oulu University Press, Vol 4, pp. 1375--1386.

Schwab, A. L., Meijaard, J. P., and Meijers P. (1998). "Dynamics of flexible multibody sytems with joint clearance," In Ghosh, A., Sinha, P. K., Dasgupta, G., and Kundu, S. (eds), Proceedings of the International Conference on

Theoretical, Applied, Computational and Experimental Mechanics, December 1--5 1998, Aerospace Engineering Department, Indian Institute of Technology, Kharagpur, India, $12 \mathrm{pp}$.

Schwab, A. L., and Meijaard, J. P. (1997). "Small vibrations superimposed on non-linear rigid body motion," Proceedings of ASME Design Engineering Technical Conferences, September 14-17, 1997, Sacramento, CA, CD-ROM, ASME, New York, 7pp.

Schwab, A. L., and Meijaard, J. P. (1996). "Multibody systems and small vibrations," In Geril, P., Javor, A., Lehmann, A., and Molnar, I. (eds), Modelling and Simulation 1996, ESM'96. Society for Computer Simulation, Gent, pp. 958-962. 


\section{Personal References}

The people named below may be able to make some comment about me. None of them have been asked to serve as reference. They are just people to check with if you are trying to figure out what I am about without asking me:

Andy Ruina, Cornell University, Ithaca, NY, USA.

Ahmed Shabana, University of Illinois at Chicage, USA.

David Limebeer, Oxford University, UK

Atanas Popov, University of Nottingham, UK.

Erno Keskinen, Tampere University of Technology, Finland.

Aki Mikkola, Lappeenranta University of Technology, Finland.

Ben Jonker, University of Twente, The Netherlands.

Hans Pacejka, Delft University of Technology, The Netherlands. 